\title{
Supporting Information \\ Variochelins, lipopeptide siderophores from Variovorax boronicumulans discovered by genome mining
}

Colette Kurth, Sebastian Schieferdecker, Kalliopi Athanasopoulou, Ivana Seccareccia, and Markus Nett*

\section{Table of Contents}

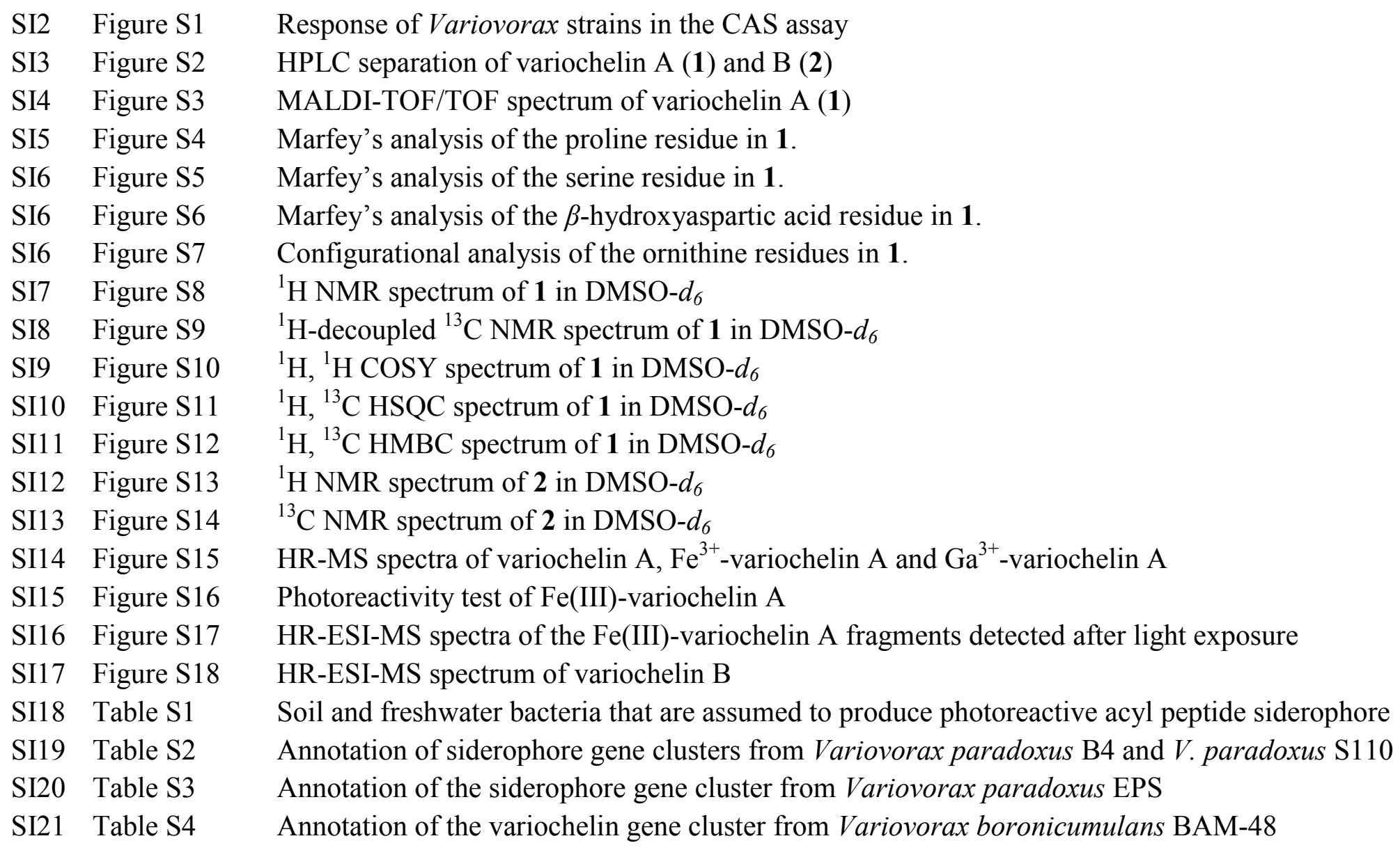


Figure S1. Response of Varivorax paradoxus B4 (a), V. paradoxus S110 (b), V. paradoxus 351, B13-0-1 D (c), V. boronicumulans BAM-48 (d), and $V$. soli GH9-3 (e) in the CAS assay. Plate (f) shows a negative control.
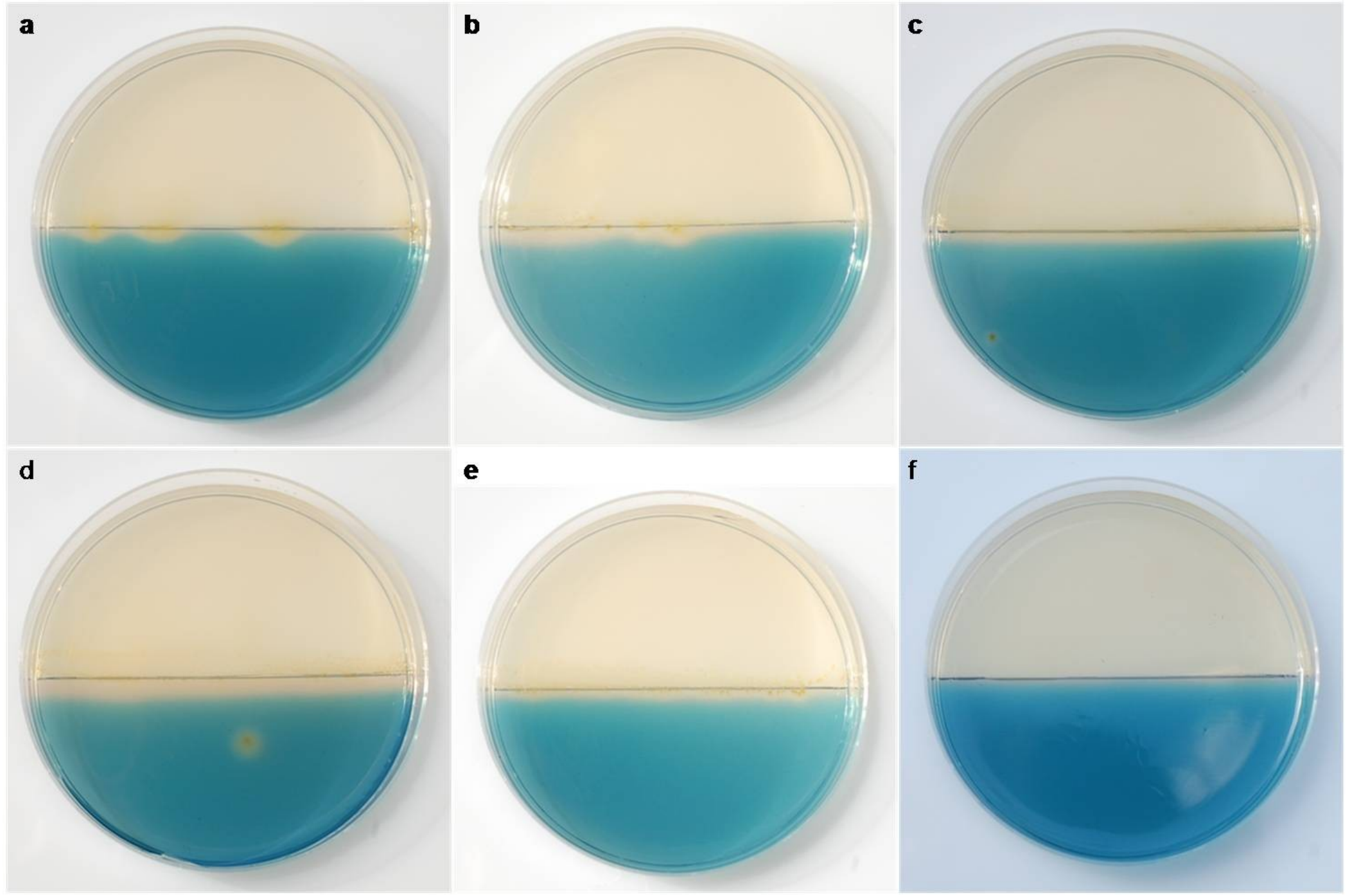
Figure S2. HPLC separation of variochelin A (1) and B (2) monitored at $190 \mathrm{~nm}$ (A). Both compounds were positive in the liquid CAS assay (B).

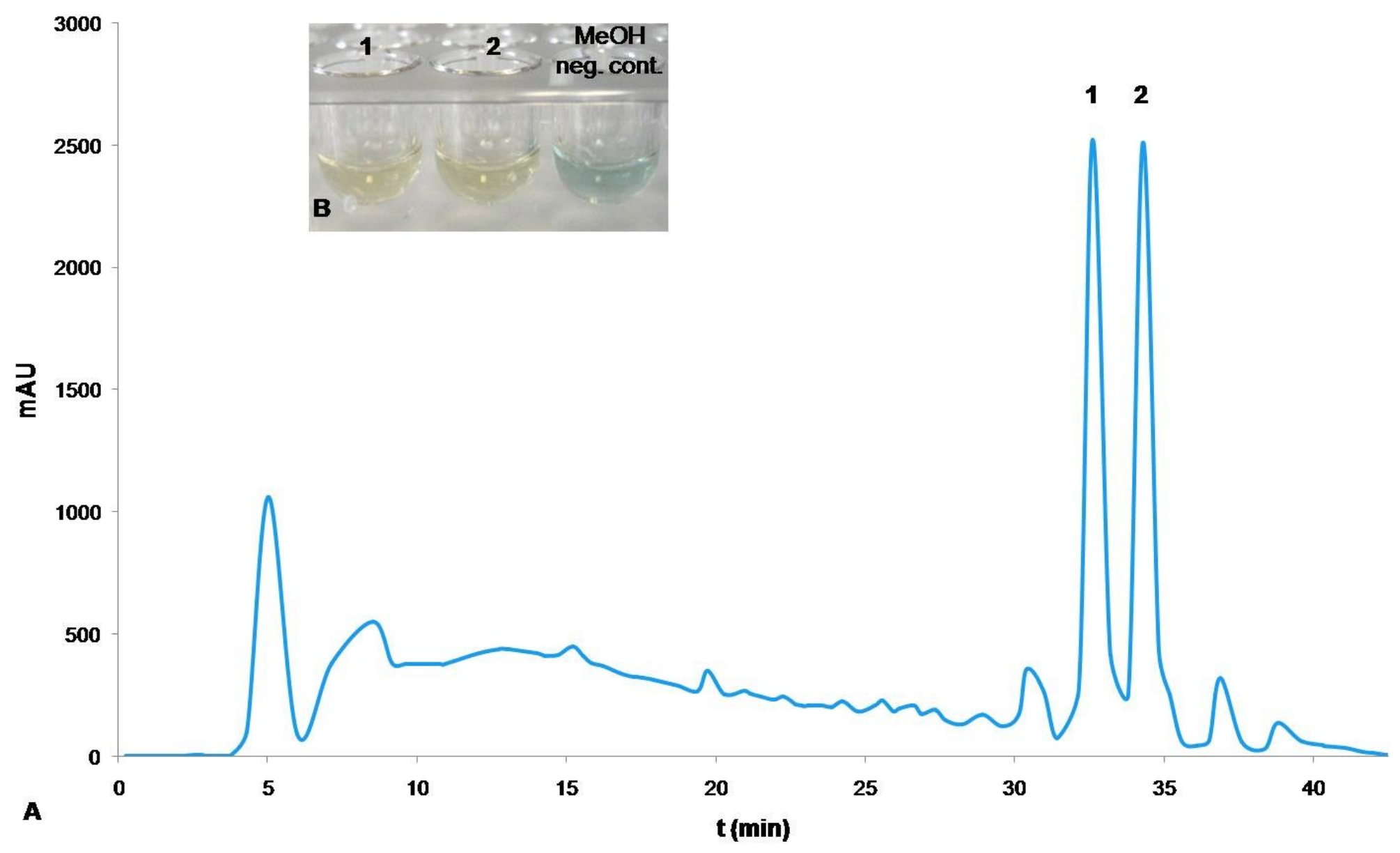


Figure S3. MALDI-TOF/TOF spectrum of variochelin A (1).

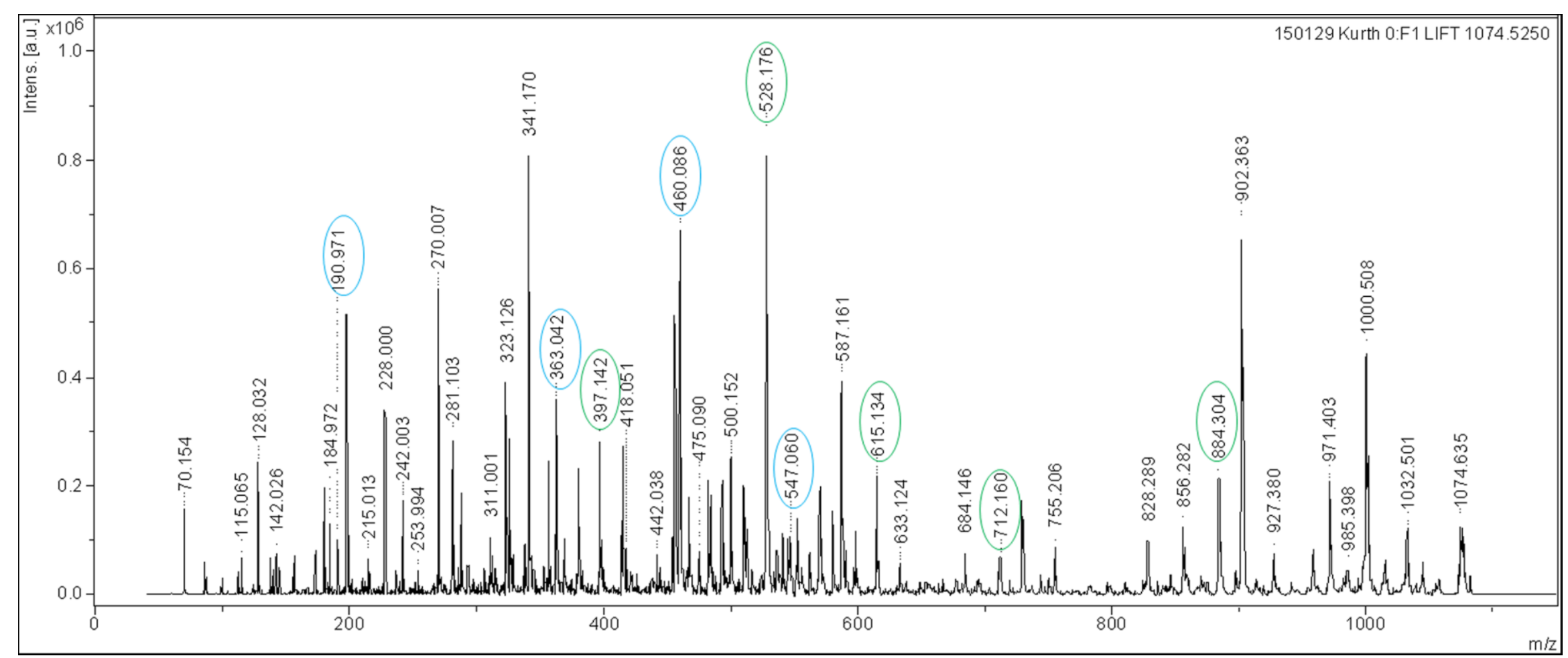


Figure S4. Marfey's analysis of the proline residue in 1. Extracted ion chromatograms of Marfey products after HI cleavage of 1 (A), from commercial L-proline (B) and D-proline (C).

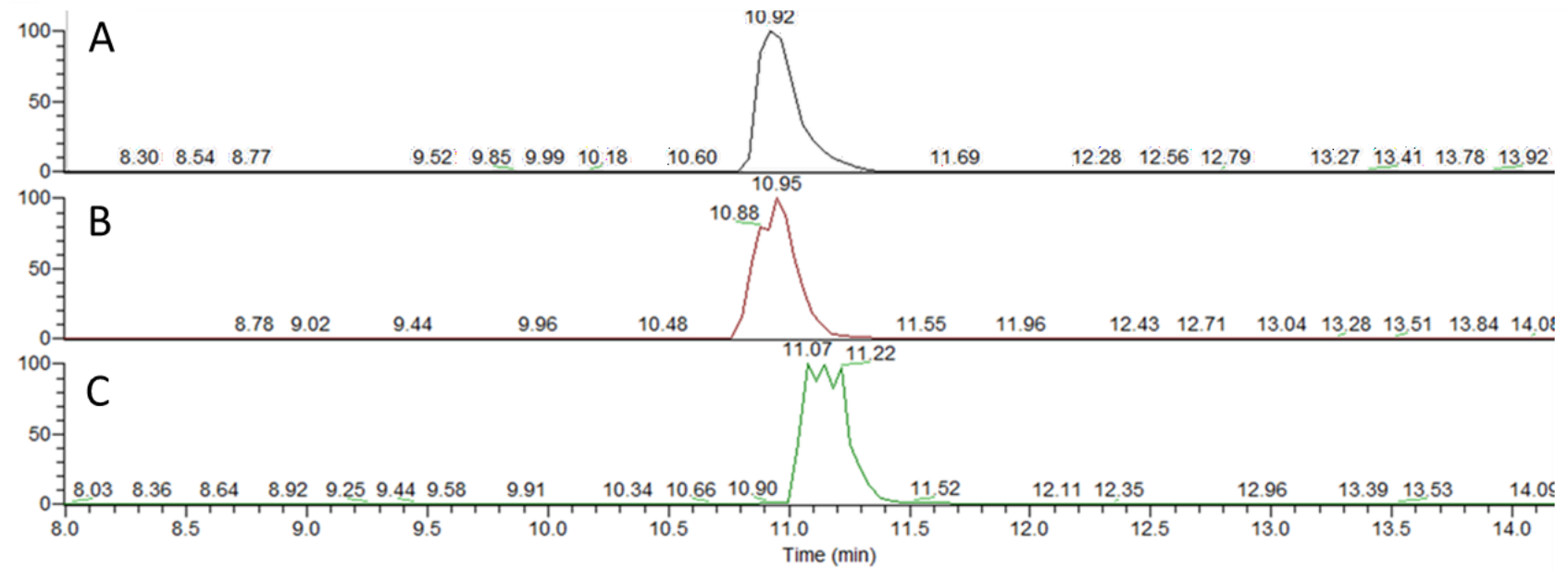

Figure S5. Marfey's analysis of the serine residue in 1. Extracted ion chromatograms of Marfey products after HI cleavage of 1 (A), from commercial L-serine (B) and D-serine (C).

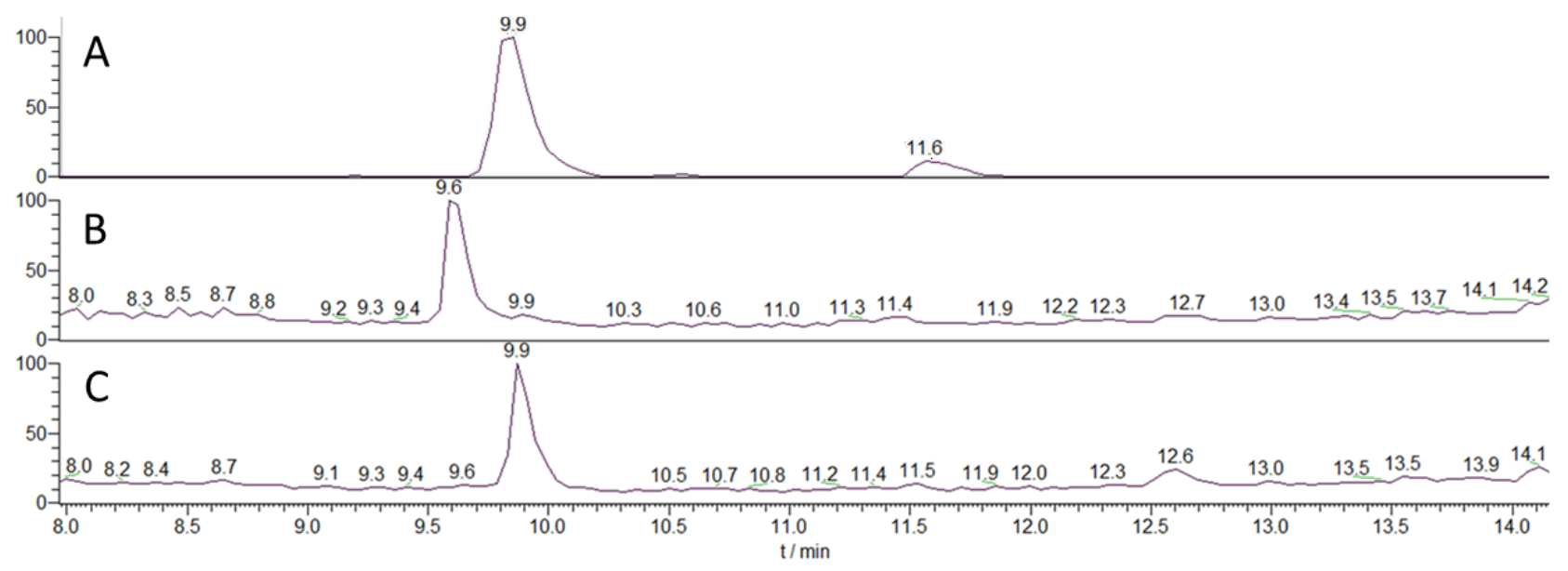


Figure S6. Marfey's analysis of the $\beta$-hydroxyaspartic acid residue in 1. UV profiles of Marfey products after HI cleavage of 1 (A) and from commercial D/L-threo- $\beta$-hydroxyaspartic acid (B).

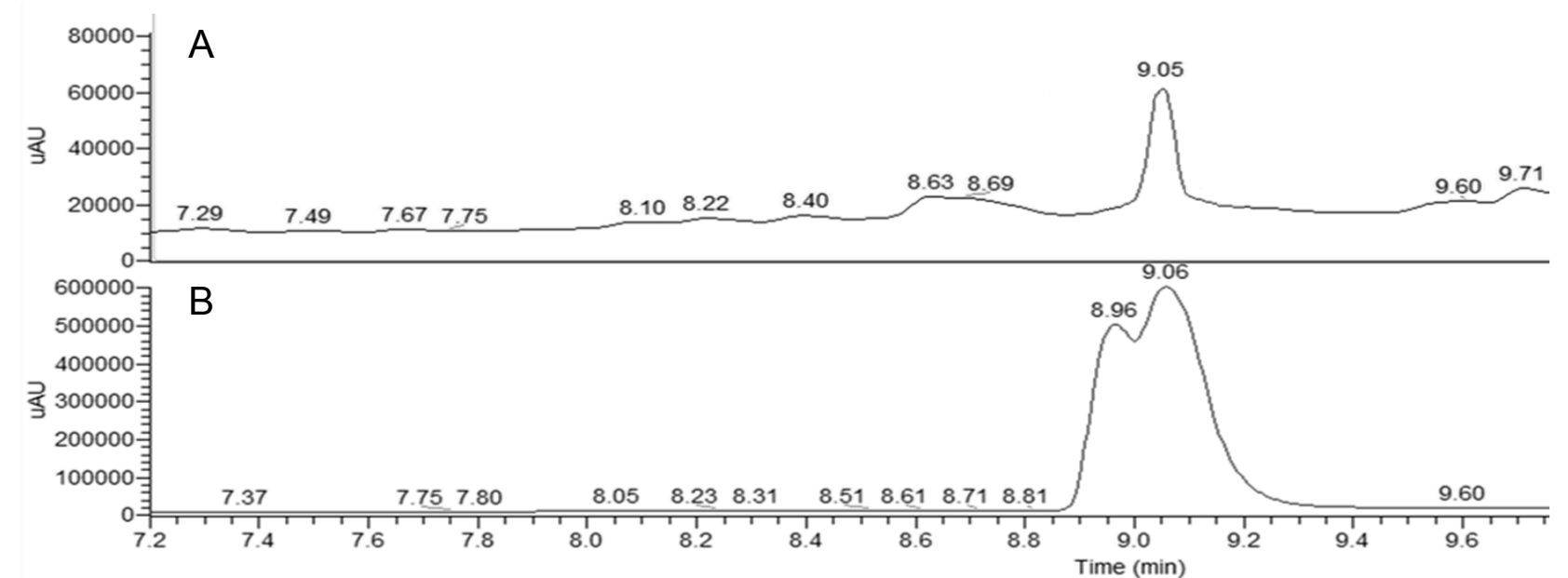

Figure S7. Configurational analysis of the ornithine residues in 1. Extracted ion chromatograms of bis-carbamate products after HI cleavage of 1 (A), from commercial D/L-ornithine (B), and from L-ornithine (C).

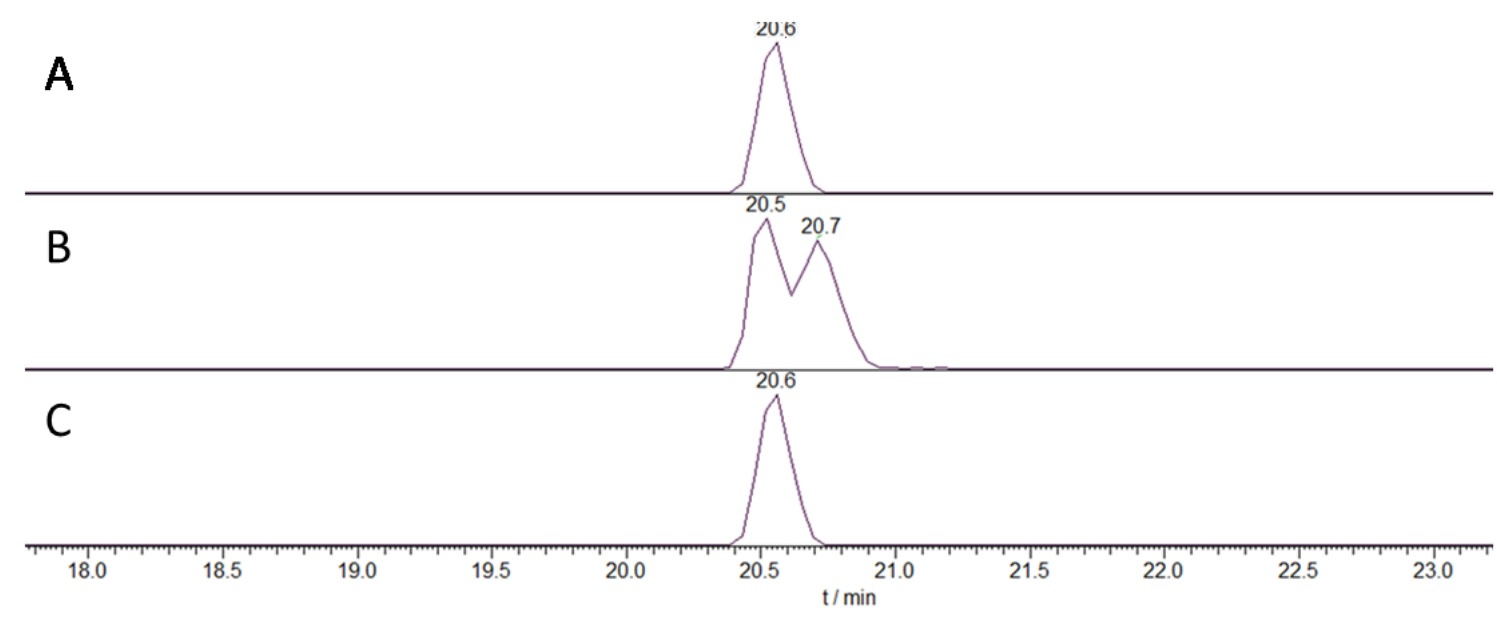


Figure S8. ${ }^{1} \mathrm{H}$ NMR $(500 \mathrm{MHz})$ spectrum of 1 in DMSO- $d_{6}$

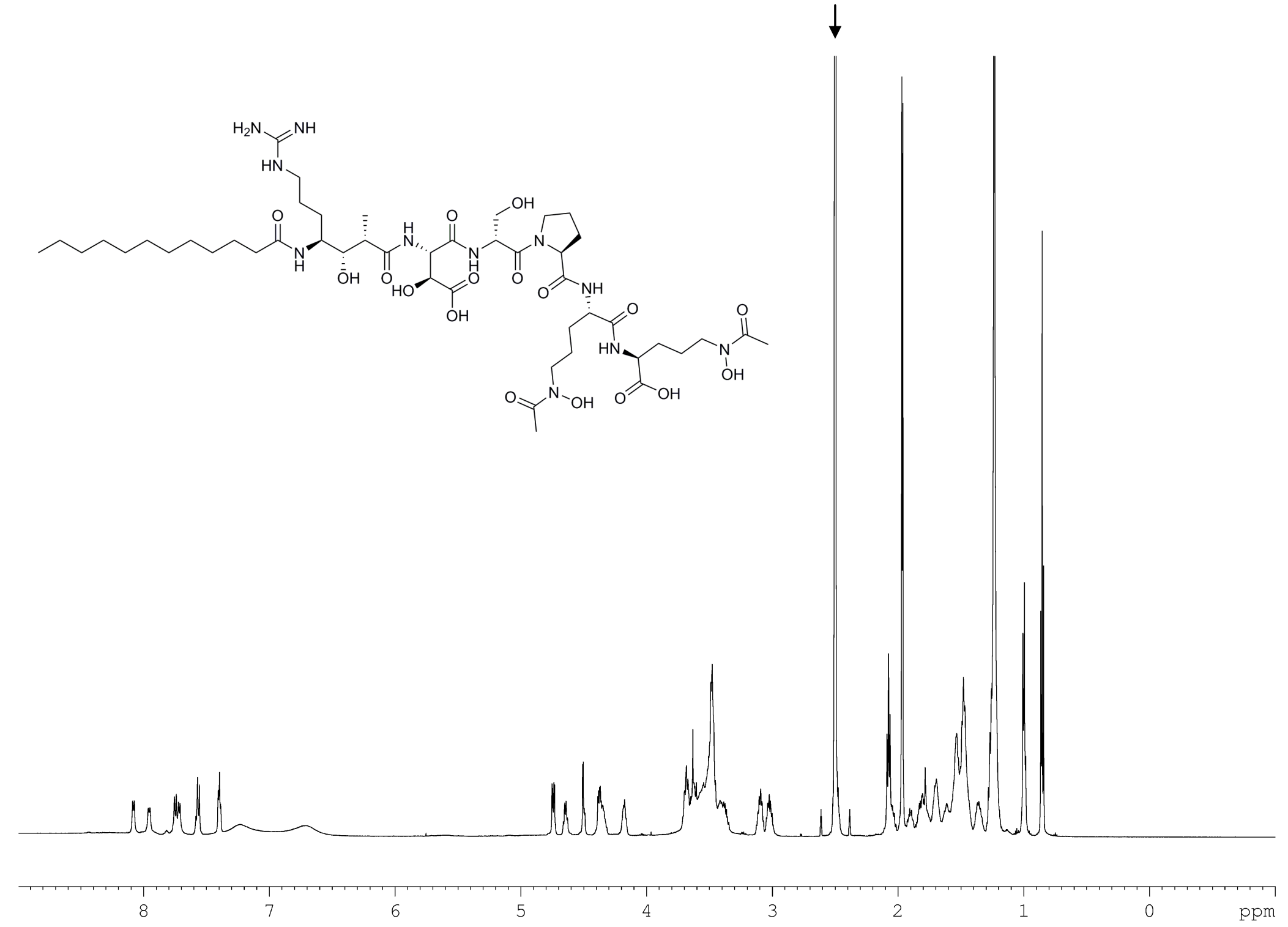


Figure S9. ${ }^{1} \mathrm{H}$-decoupled ${ }^{13} \mathrm{C}$ NMR $(125 \mathrm{MHz})$ spectrum of $\mathbf{1}$ in DMSO- $d_{6}$

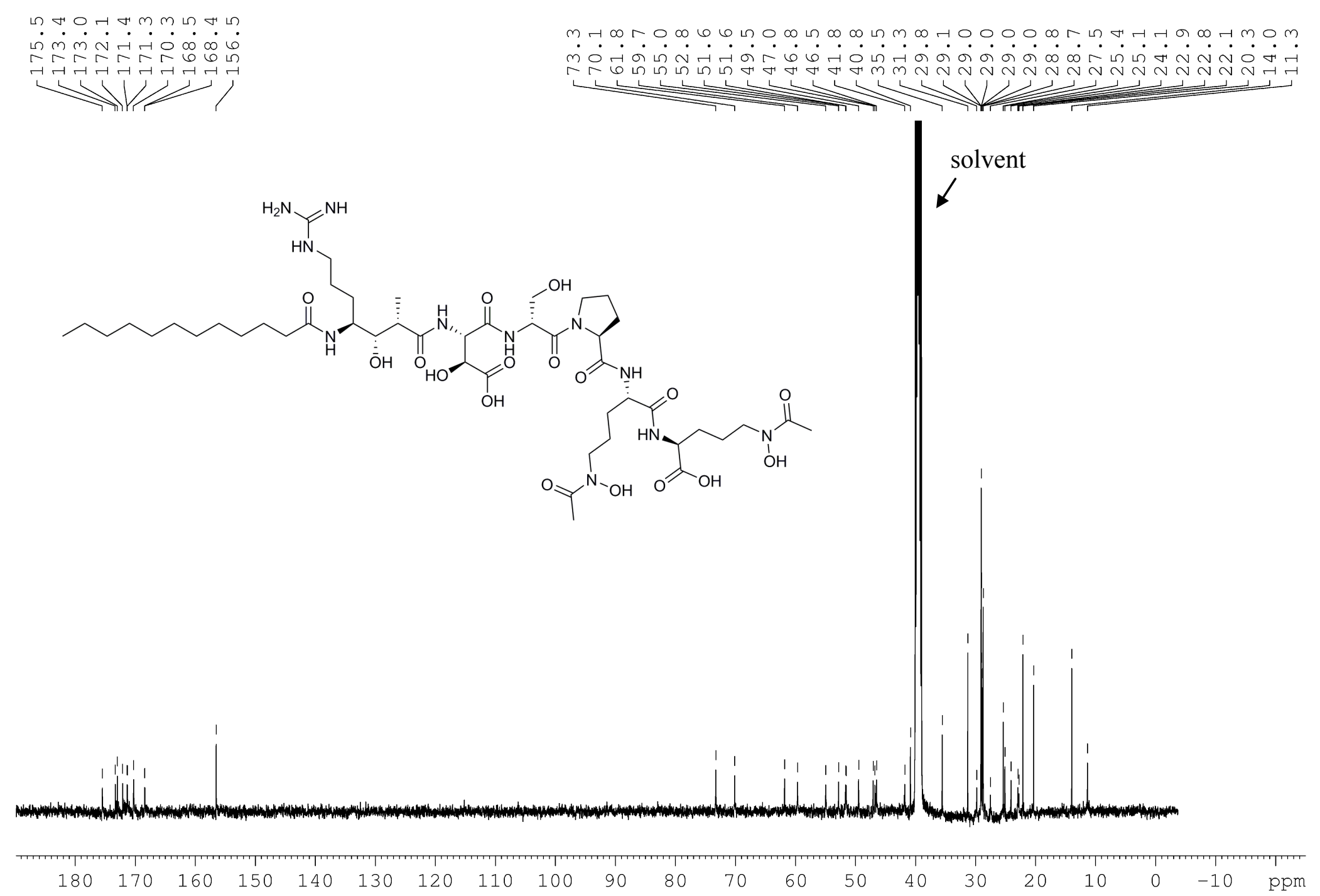


Figure S10. ${ }^{1} \mathrm{H},{ }^{1} \mathrm{H}$ COSY spectrum $(500 \mathrm{MHz})$ of $\mathbf{1}$ in DMSO- $d_{6}$

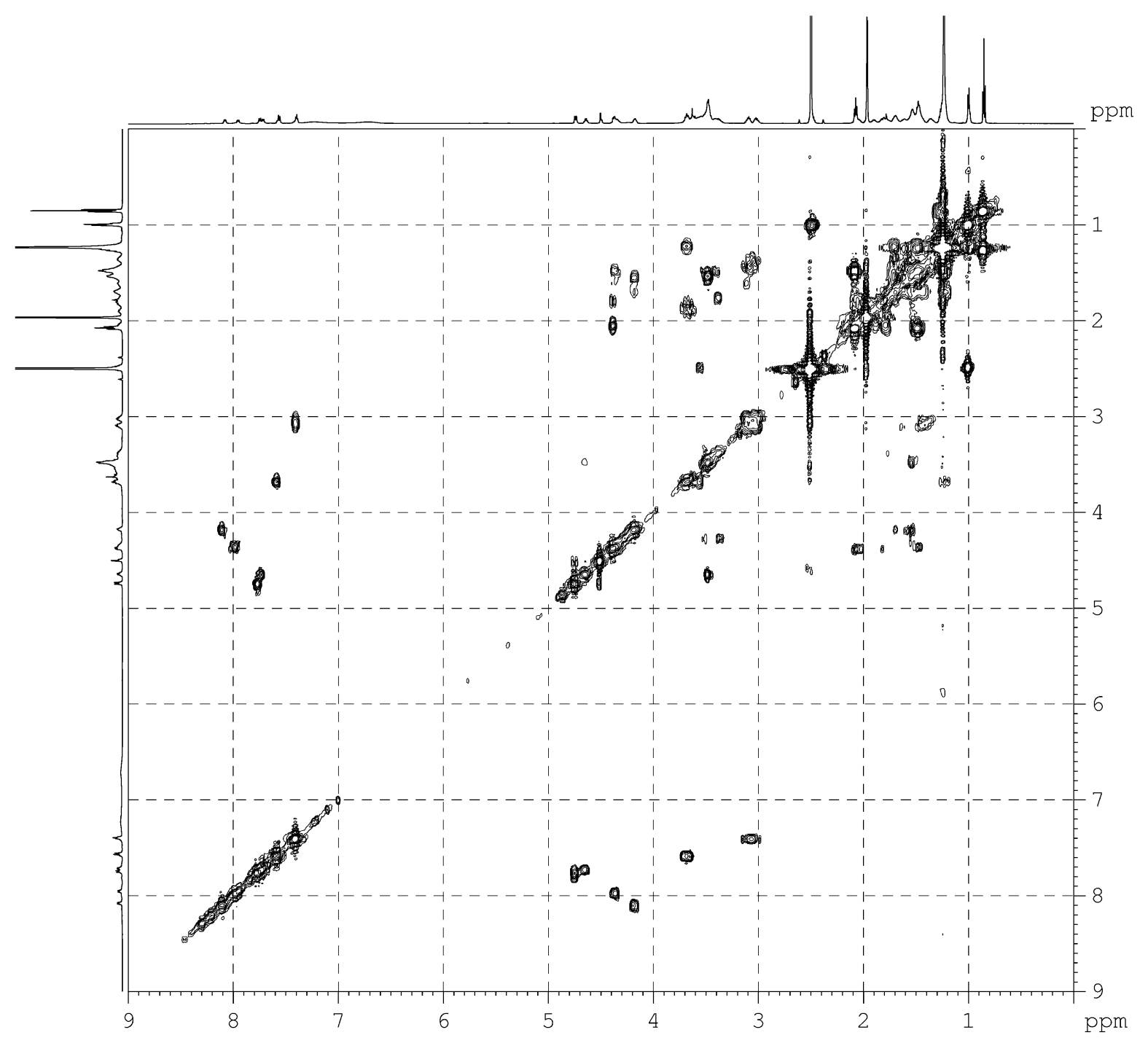


Figure S11. ${ }^{1} \mathrm{H},{ }^{13} \mathrm{C}$ HSQC (500 MHz) spectrum of $\mathbf{1}$ in DMSO- $d_{6}$

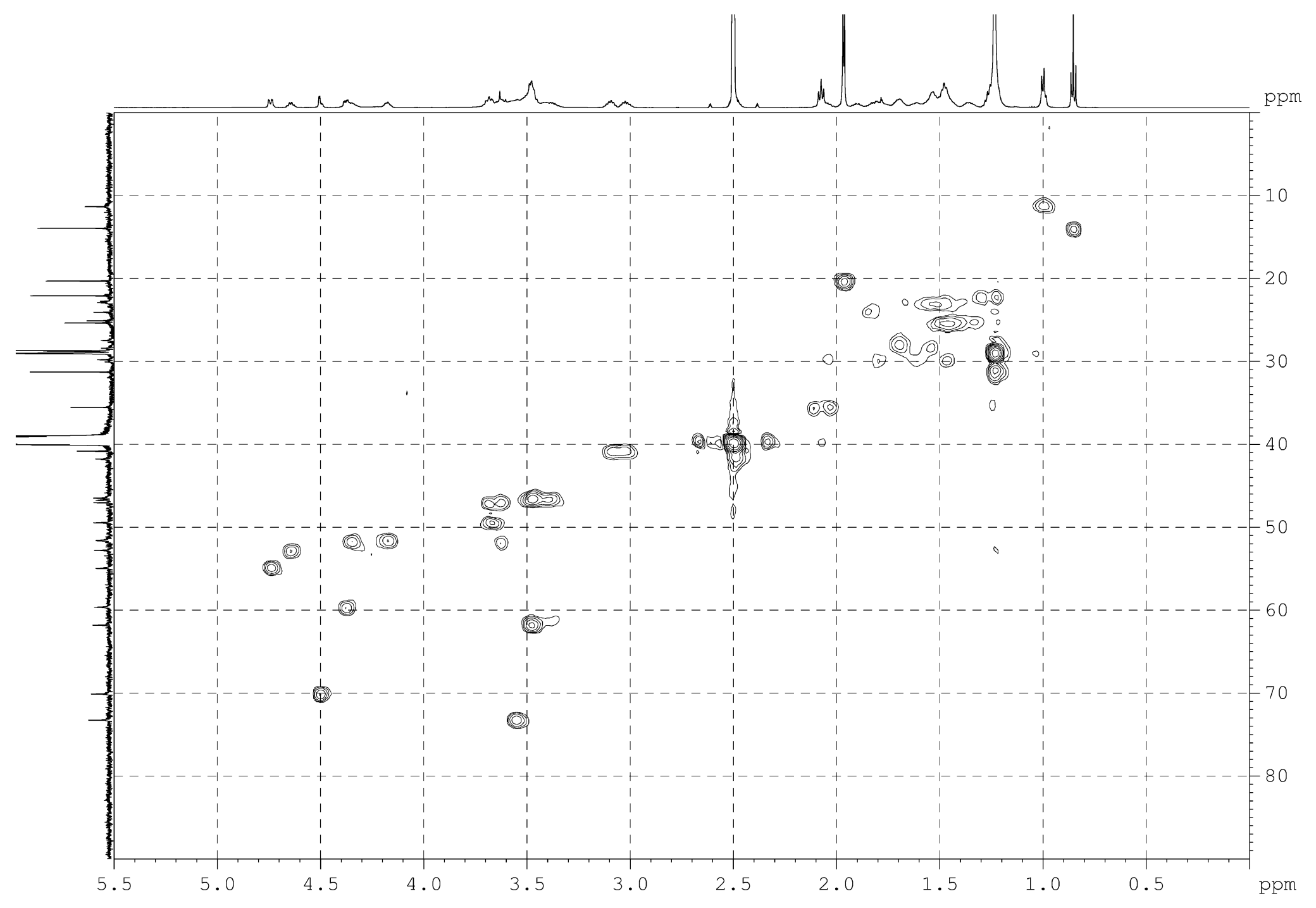


Figure S12. ${ }^{1} \mathrm{H},{ }^{13} \mathrm{C}$ HMBC $(500 \mathrm{MHz})$ spectrum of $\mathbf{1}$ in DMSO- $d_{6}$

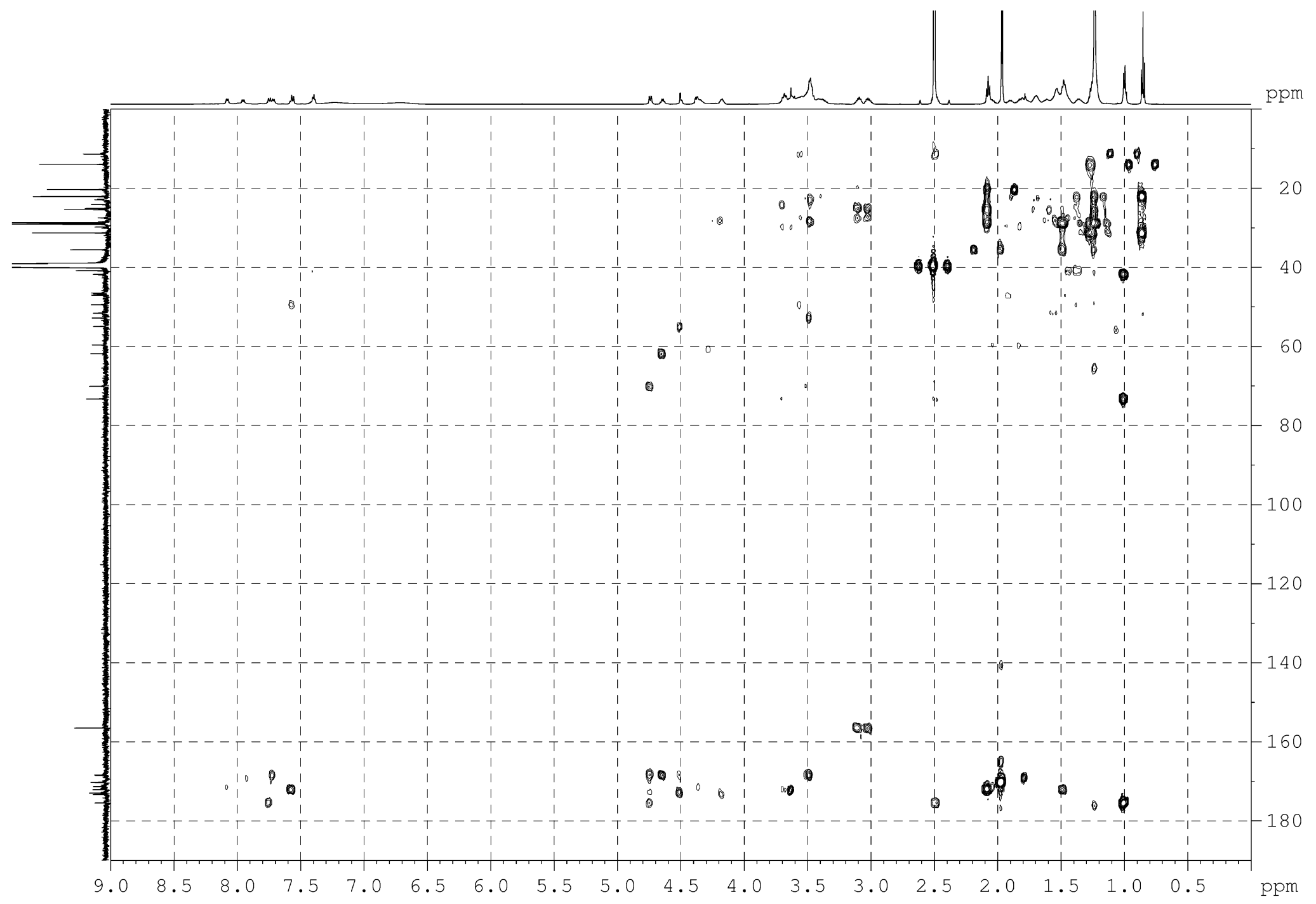


Figure S13. ${ }^{1} \mathrm{H}$ NMR $(500 \mathrm{MHz})$ spectrum of 2 in DMSO- $d_{6}$

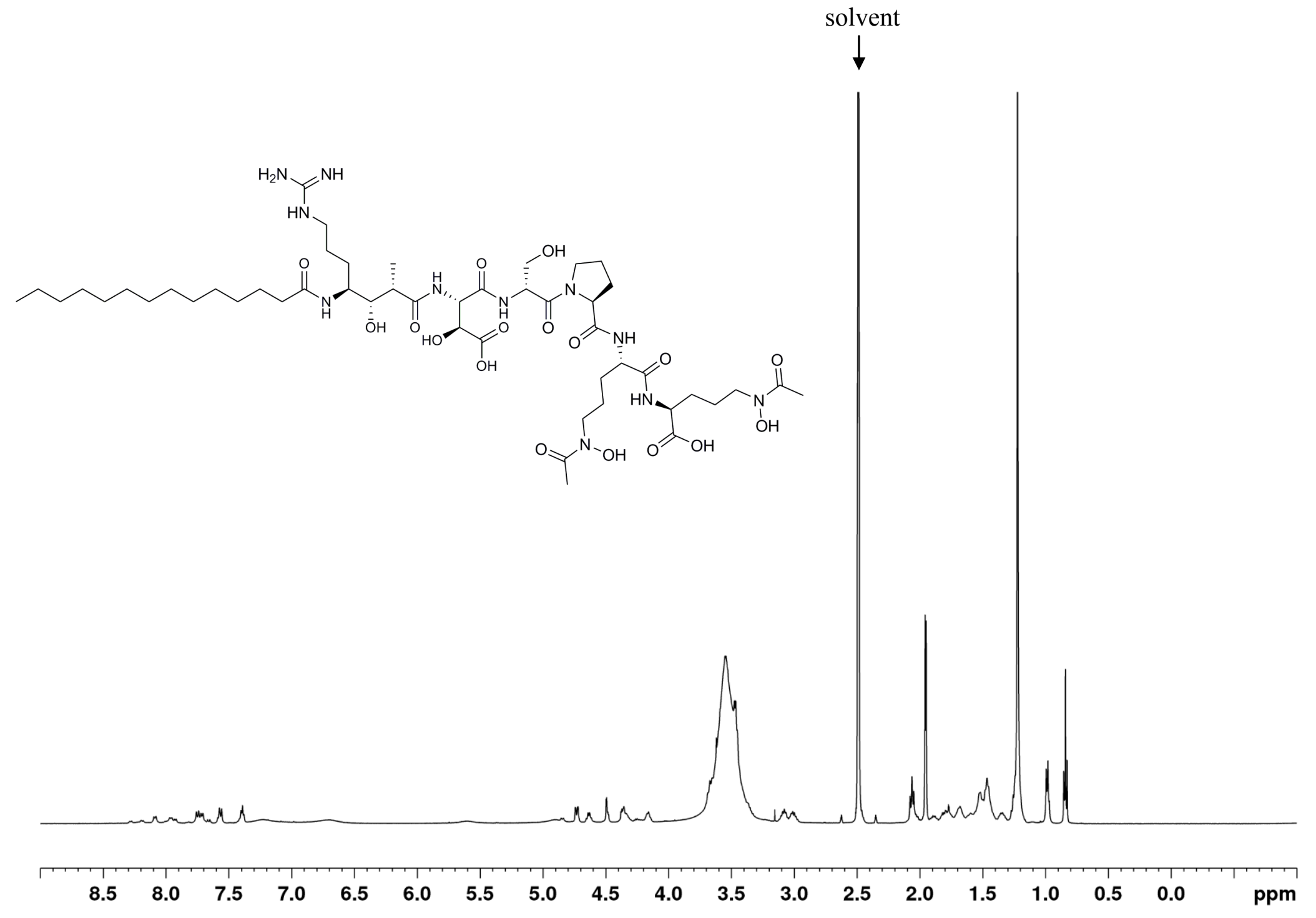


Figure S14. ${ }^{1} \mathrm{H}$-decoupled ${ }^{13} \mathrm{C}$ NMR (125 MHz) spectrum of $\mathbf{2}$ in DMSO- $d_{6}$

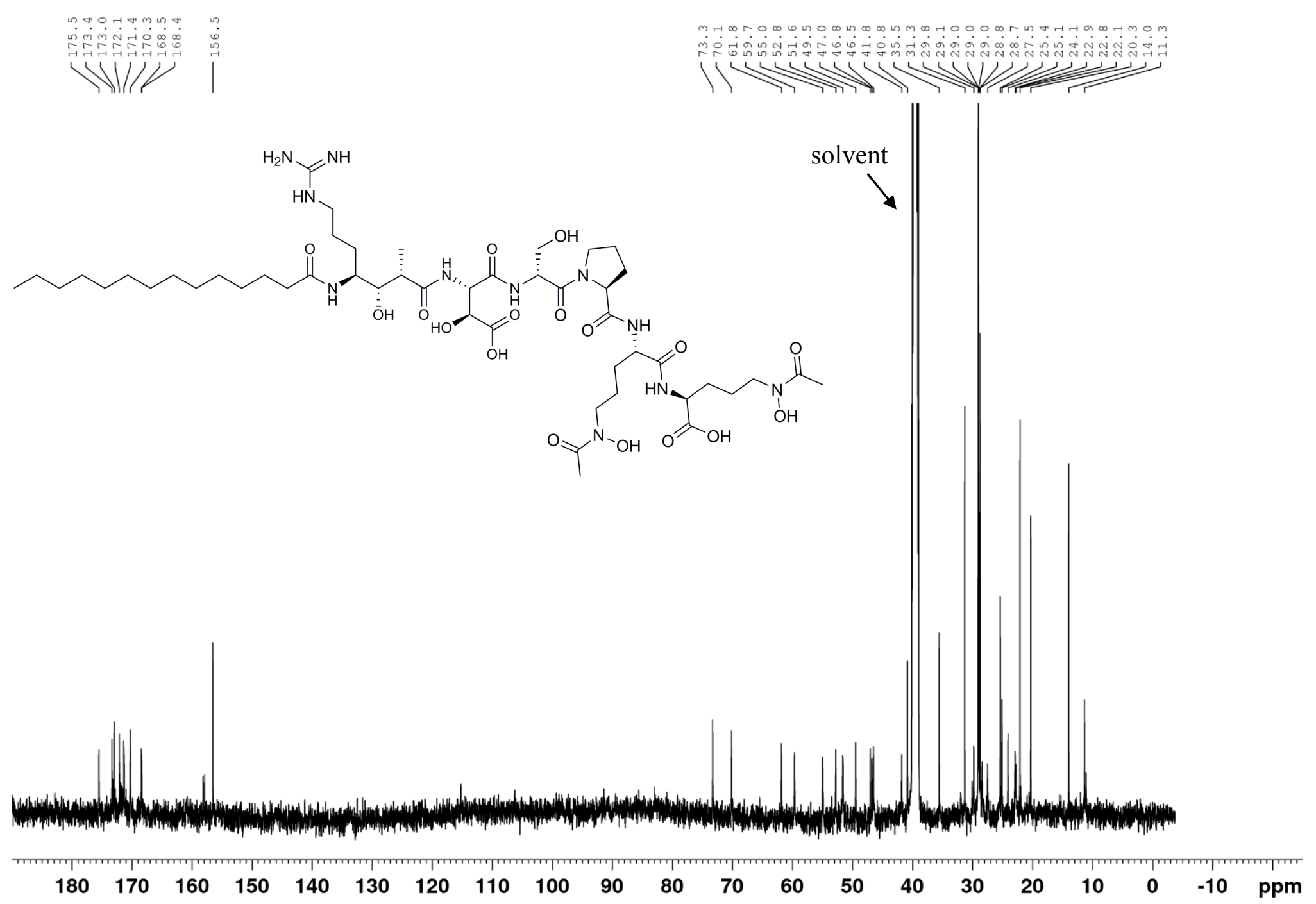


Figure S15. HR-ESI-MS spectra of variochelin A as a free ligand (top), and in complex with $\mathrm{Fe}^{3+}$ (middle) and Ga ${ }^{3+}$ (bottom).

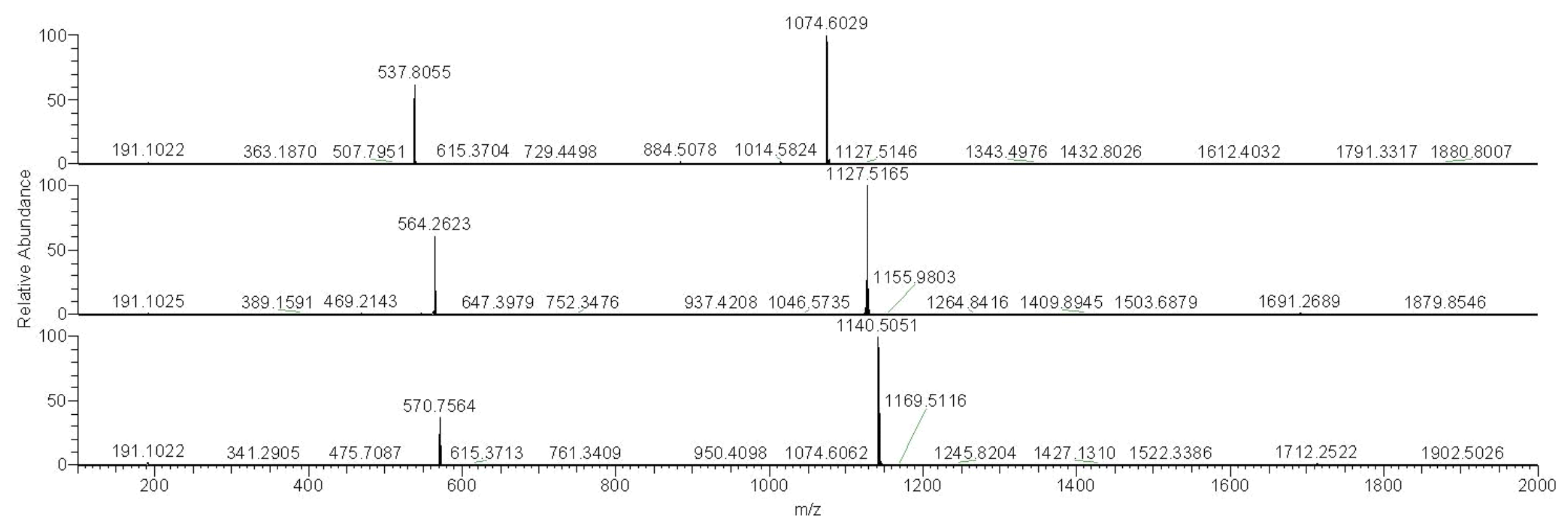


Figure S16. Photoreactivity test. LC-HR-MS of Fe(III)-variochelin A exposed to sunlight (A) and stored in the dark (B). The fragments of pseudomolecular ions with $m / \mathrm{z} 1026[\mathrm{M}-\mathrm{H}]^{-}$and $m / z 414[\mathrm{M}+\mathrm{H}]^{+}$are only observed after light exposure.

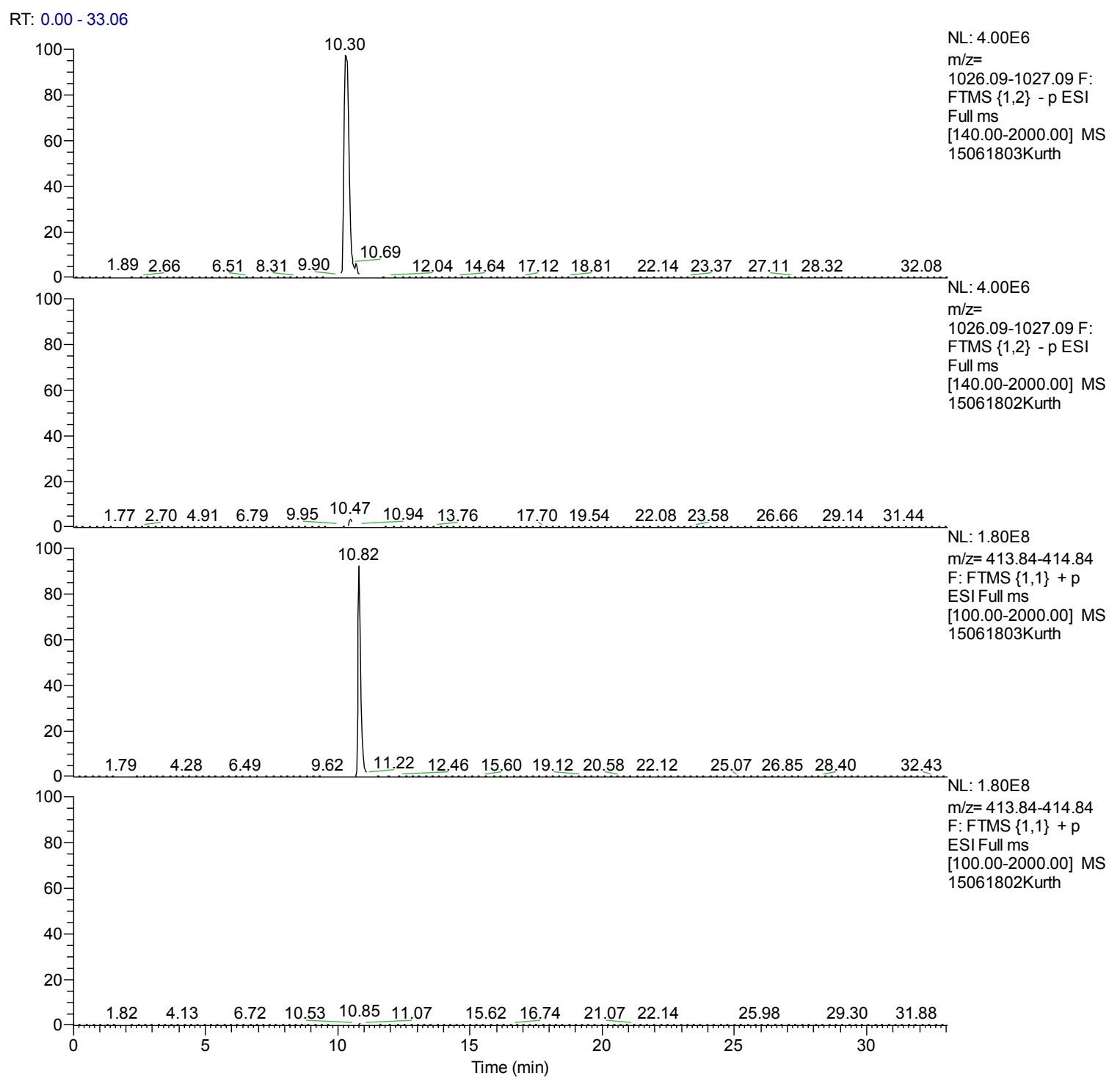


Figure S17. HR-ESI-MS spectra of the two Fe(III)-variochelin A fragment detected after light exposure.

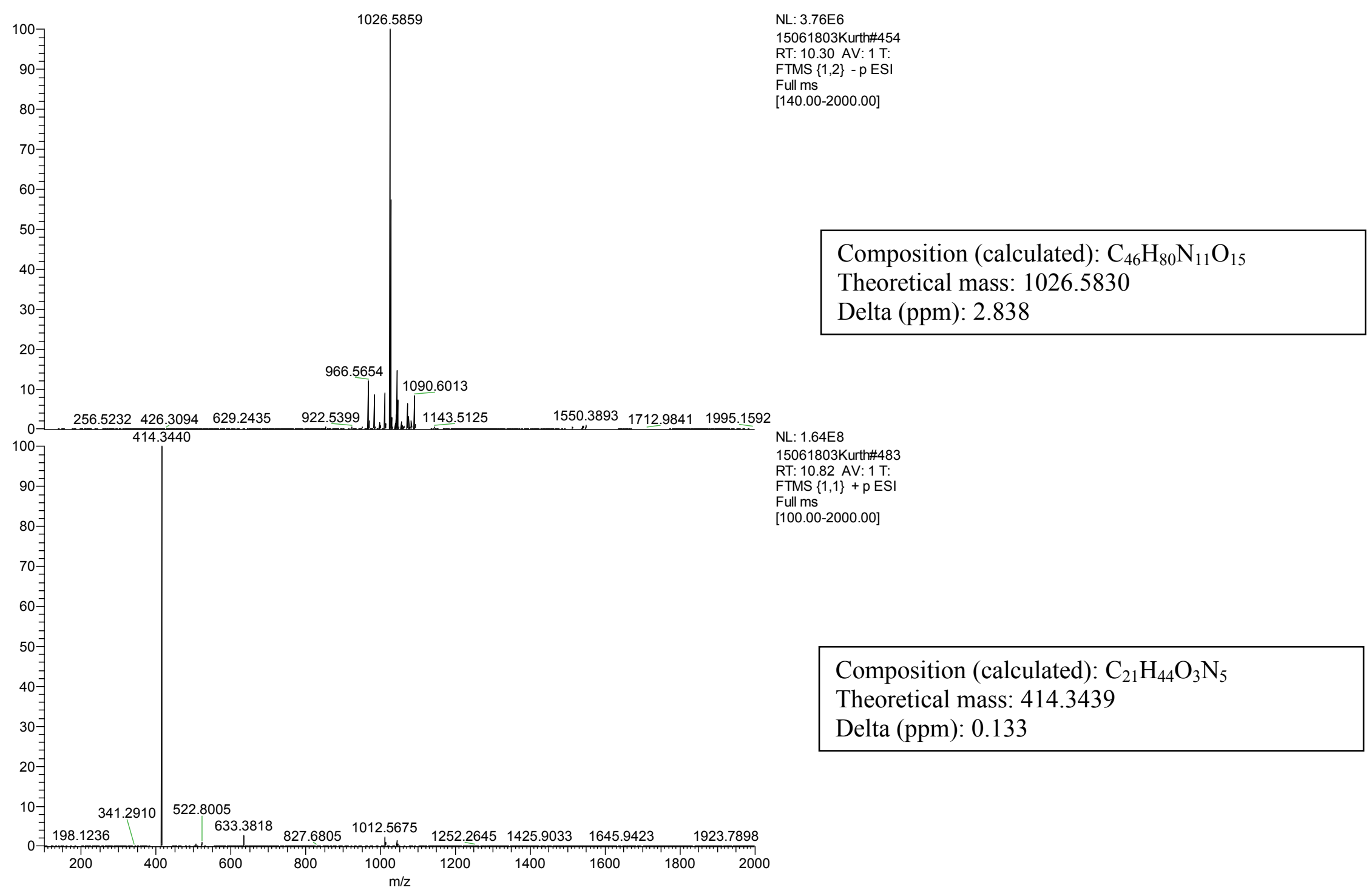


Figure S18. HR-ESI-MS spectrum of variochelin B.

14102204Kurth \#503 RT: 11.62 AV: 1 NL: 4.36E7 T: FTMS $\{1,1\}+p$ ESI Full ms [100.00-2000.00]

${ }^{100} \mathrm{z}$

95-

90 年

85

$80=$

$75-$

$70-$

$65-$

60

55 年 551.8219

$50=$

40 글

$35=$

30

25

20

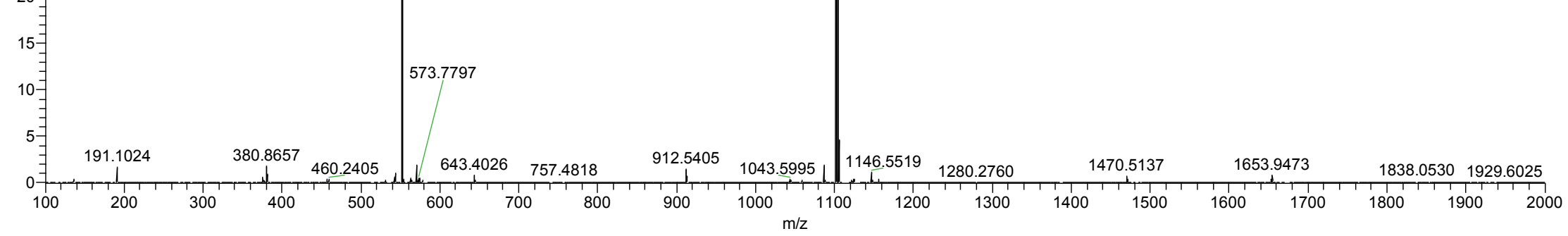


Table S1. Soil and freshwater bacteria that are assumed to produce photoreactive acyl peptide siderophore.

\begin{tabular}{|c|c|c|c|c|c|c|}
\hline & $\begin{array}{c}\text { CucG A domain } \\
\text { homolog (Identity [\%]) }\end{array}$ & $\begin{array}{c}\text { CucF TauD domain } \\
\text { homolog (Identity [\%]) }\end{array}$ & $\begin{array}{l}\text { CucF starter C domain } \\
\text { homolog (Identity [\%]) }\end{array}$ & $\begin{array}{l}\text { TaiD FAAL domain } \\
\text { homolog (Identity [\%]) }\end{array}$ & $\begin{array}{l}\text { Predicted } \\
\text { siderophore }\end{array}$ & Reference $^{1}$ \\
\hline $\begin{array}{l}\text { Achromobacter spanius } \\
\text { CGMCC } 9173\end{array}$ & WP_050444824(51) & WP_050444825(71) & - & WP_050444825 (71) & new & \\
\hline Burkholderia sordidicola $\mathrm{S} 170$ & WP_051887899 (42) & WP_051887896(68) & - & WP_051887899(56) & new & \\
\hline Cupriavidus basilensis OR16 & EHP40329 (38) & EHP40328 (73) & - & EHP40327 (76) & taiwachelin & {$[21]$} \\
\hline Cupriavidus gilardii CR3 & WP_053823544 (44) & ALD92493 (45) & - & WP_053823547(52) & new & \\
\hline Cupriavidus necator $\mathrm{H} 16$ & WP_011617407 (100) & WP_011617408(100) & WP_011617408(100) & - & cupriachelin & {$[20]$} \\
\hline Cupriavidus sp. amp6 & WP_051320452 (44) & WP_051320452 (94) & WP_051320452(83) & - & cupriachelin & {$[20]$} \\
\hline Cupriavidus sp. SK-4 & EYS85590 (97) & EYS85589 (99) & EYS85589 (97) & - & cupriachelin & {$[20]$} \\
\hline Cupriavidus sp. WS & WP_020206421 (46) & WP_020206420(75) & - & WP_020206420(72) & taiwachelin & {$[21]$} \\
\hline $\begin{array}{l}\text { Cupriavidus taiwanensis LMG } \\
19424\end{array}$ & WP_012356046 (47) & WP_012356045(73) & - & WP_012356045 (100) & taiwachelin & {$[21]$} \\
\hline Herbaspirillum seropedicae Z67 & AKN68207 (43) & AKN68207 (71) & - & AKN68207 (36) & serobactin & {$[22]$} \\
\hline $\begin{array}{l}\text { Janthinobacterium } \\
\text { agaricidamnosum NBRC } 102515\end{array}$ & CDG82376 (43) & CDG82376 (72) & - & CDG82375 (57) & new & \\
\hline Ralstonia pickettii DTP0602 & AGW94292 (93) & AGW94293 (98) & AGW94293 (93) & - & cupriachelin & {$[20]$} \\
\hline Ralstonia sp. GA3-3 & EON20600 (99) & EON20601 (100) & EON20601 (99) & - & cupriachelin & {$[20]$} \\
\hline Variovorax paradoxus B4 & WP_021008405 (40) & WP_021008410 (42) & - & WP_021008409(55) & new & \\
\hline Variovorax paradoxus EPS & WP_013542707 (37) & ADU35203 (55) & - & WP_013542707 (55) & new & \\
\hline Variovorax paradoxus $\mathrm{S} 110$ & WP_015866520(41) & WP_015866525(42) & - & WP_015866524(56) & new & \\
\hline
\end{tabular}

${ }^{1}$ see main manuscript 
Table S2. Annotation of siderophore gene clusters from Variovorax paradoxus B4 and V. paradoxus S110.

\begin{tabular}{|c|c|c|c|c|}
\hline Gene & Protein accession no. (GenBank) & Size (aa) & Proposed function (domain architecture) & Predicted substrate specificity $^{1}$ \\
\hline VAPA_1c38580/Vapar_3733 & WP_021008396/WP_015866511 & $206 / 207$ & DNA-directed RNA polymerase sigma-70 factor & \\
\hline VAPA_1c38590/Vapar_3734 & WP_021008397 / WP_015866512 & $72 / 72$ & anti-FecI sigma factor FecR & \\
\hline VAPA_1c38600/Vapar_3735 & WP_021008398/WP_015866513 & $78 / 78$ & hypothetical protein & \\
\hline VAPA_1c38610/Vapar_3736 & WP_021008399/WP_015866514 & $563 / 563$ & peptide transporter & \\
\hline VAPA_1c38620/Vapar_3737 & WP_021008400/WP_015866515 & $281 / 281$ & ferric iron reductase & \\
\hline VAPA_1c38630/Vapar_3738 & WP_021008401/WP_015866516 & $281 / 281$ & $\mathrm{~N}$-hydroxyornithine formyltransferase & \\
\hline VAPA_1c38640 / Vapar_3739 & WP_021008402/WP_015866517 & $344 / 344$ & $N$-hydroxyornithine acetyltransferase & \\
\hline VAPA_1c38650/Vapar_3740 & WP_021008403/WP_015866518 & $450 / 439$ & ornithine $N$-monooxygenase & \\
\hline VAPA_1c38660/Vapar_3741 & WP_021008404/WP_015866519 & $722 / 723$ & TonB-dependent receptor & \\
\hline VAPA_1c38670/Vapar_3742 & WP_021008405/WP_015866520 & $1357 / 1358$ & non-ribosomal peptide synthetase (C-A-PCP-TE) & aspartic acid \\
\hline VAPA_1c38680/Vapar_3743 & WP_021008406/WP_015866521 & $2625 / 2626$ & non-ribosomal peptide synthetase (C-A-PCP-E-C-A-PCP) & $\mathrm{N}^{\delta}$-hydroxyornithine + threonine \\
\hline VAPA_1c38690/Vapar_3744 & WP_021008407 / WP_015866522 & $1113 / 1110$ & non-ribosomal peptide synthetase (C-A-PCP) & serine \\
\hline VAPA_1c38700 / Vapar_3745 & WP_021008408/WP_015866523 & $1520 / 1520$ & polyketide synthase (KS-AT-KR-ACP) & malonyl-CoA \\
\hline VAPA_1c38710/Vapar_3746 & WP_021008409/WP_015866524 & $1771 / 1776$ & non-ribosomal peptide synthetase (FAAL-ACP-C-A-PCP) & $\begin{array}{l}\text { fatty acid }+ \\
\mathrm{N}^{\delta} \text {-formyl- } \mathrm{N}^{\delta} \text {-hydroxyornithine }\end{array}$ \\
\hline VAPA_1c38720 / Vapar_3747 & WP_021008410/WP_015866525 & $330 / 330$ & TauD-like hydroxylase & \\
\hline VAPA_1c38730/Vapar_3748 & WP_021008411/WP_015866526 & $229 / 229$ & 4'-phosphopantetheinyl transferase & \\
\hline VAPA_1c38740/Vapar_3749 & WP_021008412/WP_015866527 & $245 / 246$ & type II thioesterase & \\
\hline VAPA_1c38750/Vapar_3750 & WP_021008413/WP_015866528 & $85 / 85$ & MbtH domain-containing protein & \\
\hline VAPA_1c38760/Vapar_3751 & WP_021008414/WP_015866529 & $67 / 67$ & anti-FecI sigma factor FecR & \\
\hline VAPA_1c38770 / Vapar_3752 & WP_021008415/WP_015866530 & $181 / 181$ & DNA-directed RNA polymerase sigma-70 factor & \\
\hline
\end{tabular}


Table S3. Annotation of the siderophore gene cluster from Variovorax paradoxus EPS.

\begin{tabular}{|c|c|c|c|c|}
\hline Gene & $\begin{array}{c}\text { Protein accession } \\
\text { no. (GenBank) }\end{array}$ & $\begin{array}{l}\text { Size } \\
\text { (aa) }\end{array}$ & Proposed function (domain architecture) & Predicted substrate specificity $^{1}$ \\
\hline Varpa_4319 & WP_013542699 & 433 & ornithine $N$-monooxygenase & \\
\hline Varpa_4320 & WP_013542700 & 559 & peptide transporter & \\
\hline Varpa_4321 & WP_013542701 & 288 & ferric iron reductase & \\
\hline Varpa_4322 & WP_013542702 & 280 & $N$-hydroxyornithine formyltransferase & \\
\hline Varpa_4323 & WP_013542703 & 721 & TonB-dependent siderophore receptor & \\
\hline Varpa_4324 & WP_013542704 & 4633 & non-ribosomal peptide synthetase (C-A-PCP-C-A-PCP-C-A-PCP-C-A-PCP-TE) & $\begin{array}{l}\mathrm{N}^{\delta} \text {-hydroxyornithine }+\mathrm{N}^{\delta} \text {-formyl- } \mathrm{N}^{\delta} \text { - } \\
\text { hydroxyornithine }+ \text { threonine }+ \text { serine }\end{array}$ \\
\hline Varpa_4325 & WP_013542705 & 4313 & non-ribosomal peptide synthetase (C-A-PCP-C-A-PCP-C-A-PCP-C-A-PCP) & $\begin{array}{l}\mathrm{N}^{\delta} \text {-formyl- } \mathrm{N}^{\delta} \text {-hydroxyornithine }+ \text { threonine }+ \\
\text { threonine }+ \text { glycine }\end{array}$ \\
\hline Varpa_4326 & WP_013542706 & 1542 & polyketide synthase (KS-AT-KR-ACP) & malonyl-CoA \\
\hline Varpa_4327 & WP_013542707 & 1766 & non-ribosomal peptide synthetase (FAAL-ACP-C-A-PCP) & fatty acid $+\mathrm{N}^{\delta}$-formyl- $\mathrm{N}^{\delta}$-hydroxyornithine \\
\hline Varpa_4328 & WP_013542708 & 249 & type II thioesterase & \\
\hline Varpa_4329 & WP_013542709 & 84 & MbtH domain-containing protein & \\
\hline Varpa_4330 & WP_013542710 & 82 & anti-FecI sigma factor FecR & \\
\hline Varpa_4331 & WP_013542711 & 179 & DNA-directed RNA polymerase sigma-70 factor & \\
\hline Varpa_4332 & WP_013542712 & 321 & 4'-phosphopantetheinyl transferase & \\
\hline
\end{tabular}

${ }^{1}$ according to references [32-36] in the main manuscript 
Tables S4. Annotation of the variochelin gene cluster from Variovorax boronicumulans BAM-48.

\begin{tabular}{|c|c|c|c|}
\hline Gene & $\begin{array}{c}\text { Size of } \\
\text { protein (aa) }\end{array}$ & Proposed function (domain architecture) & Predicted substrate specificity $^{1}$ \\
\hline varR & 560 & peptide transporter & \\
\hline $\operatorname{var} Q$ & 78 & anti-FecI sigma factor FecR & \\
\hline $\operatorname{var} P$ & 262 & ferric iron reductase & \\
\hline varO & 369 & $N$-hydroxyornithine acetyltransferase & \\
\hline $\operatorname{varN}$ & 440 & ornithine $\mathrm{N}$-monooxygenase & \\
\hline $\operatorname{varM}$ & 193 & RNA polymerase subunit sigma-24 & \\
\hline $\operatorname{varL}$ & 343 & anti-FecI sigma factor FecR & \\
\hline $\operatorname{varK}$ & 816 & TonB-dependent receptor & \\
\hline varJ & 2459 & nonribosomal peptide synthetase (C-A-PCP-C-A-PCP-TE) & $\mathrm{N}^{\delta}$-hydroxyornithine $+\mathrm{N}^{\delta}$-hydroxyornithine \\
\hline varI & 2586 & nonribosomal peptide synthetase (C-A-PCP-E-C-A-PCP) & serine + proline \\
\hline varH & 1035 & nonribosomal peptide synthetase (C-A-PCP) & aspartic acid \\
\hline $\operatorname{var} G$ & 2351 & polyketide synthase (KS-AT-KR-ACP-C-TauD) & malonyl-CoA \\
\hline $\operatorname{varF}$ & 1756 & nonribosomal peptide synthetase (FAAL-ACP-C-A-PCP) & fatty acid + arginine \\
\hline varE & 234 & 4'-phosphopantetheinyl transferase & \\
\hline $\operatorname{varD}$ & 249 & type II thioesterase & \\
\hline $\operatorname{varC}$ & 81 & MbtH domain-containing protein & \\
\hline $\operatorname{var} B$ & 82 & anti-FecI sigma factor FecR & \\
\hline varA & 178 & DNA-directed RNA polymerase sigma-70 factor & \\
\hline
\end{tabular}

